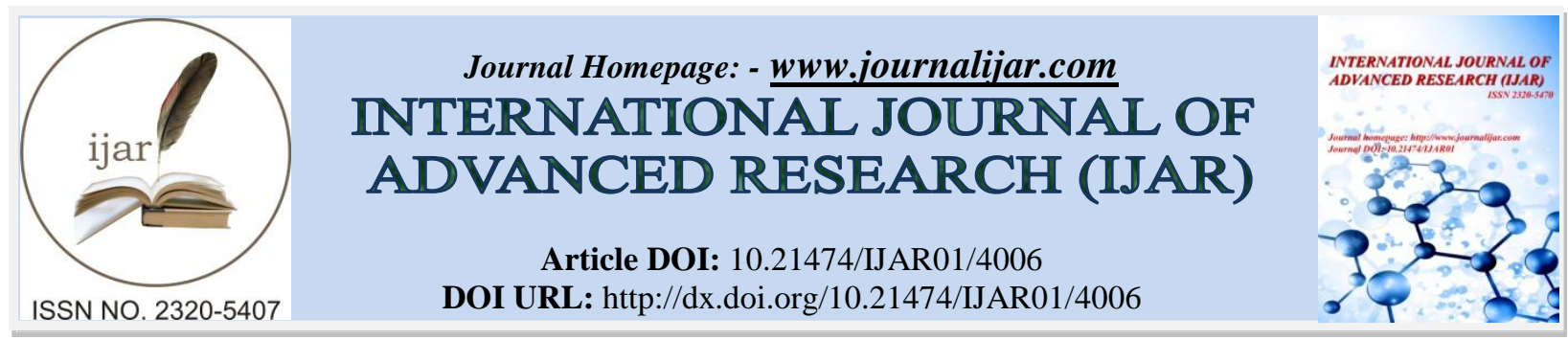

RESEARCH ARTICLE

\title{
CFD ANALYSIS OF DOUBLE TUBE HELICAL COIL HEAT EXCHANGER FOR DIFFERENT HEAT TRANSFER CHARACTERISTICS.
}

Priyanshu Dradhomar ${ }^{1}$, Subhashini Verma ${ }^{1}$,Vikas Singh ${ }^{1}$, Pallavi Dradhomar ${ }^{1}$ and Manjunatha. $\mathbf{M}^{2}$.

1. Department of mechanical engineering, JSS Academy of Technical Education, Noida, India.

2. Assistant Professor, Department of Mechanical Engineering, JSS Academy of Technical Education, Noida, India.

\section{Manuscript Info}

\section{Manuscript History}

Received: 16 February 2017

Final Accepted: 12 March 2017

Published: April 2017

\section{Abstract}

The purpose of this analysis is to determine the variation in the temperature drop, heat transfer rate and pressure when the number of turns in a double tube helical coil heat exchanger are changed. The boundary conditions are kept same but the number of turns of the coil is changed. For the analysis, ANSYS Fluent 15.0 has been used.

Copy Right, IJAR, 2017,. All rights reserved.

\section{Introduction:-}

Enhancing the heat transfer by the use of the double tube helical coil heat exchanger has been studied and researched by many researchers. It is due to the reason that the fluid dynamics inside the pipes of a double pipe helical coil heat exchanger offer certain advantages over the straight tubes, shell and tube type heat exchanger, in terms of better heat transfer and mass transfer coefficients. This helical coil heat exchanger provides the advantage of achieving high overall heat transfer coefficients and high compact structure. The two ends of the tube act as inlet and outlet manifolds. They serve the purpose of the entry and exit of hot as well as cold fluid. Through various researches, researchers have found that a complex flow pattern exists inside a helical pipe which enhances heat transfer rate. Centrifugal forces acting, are governed by the curvature of the coil. These centrifugal forces result in the development of secondary flow. The velocity of the fluid streams on the outer side of the pipe is more than the fluid streams in the inner side of the pipe. This difference in velocity sets- in secondary flows, whose pattern changes with the Dean number of the flow. Due to the helix angle, torsion to which the fluid is subjected gets influenced.

The studies and researches conducted by various researchers are as follows. Daniel Florez- Orrego, Walter arias, Diego Lopez and hector Velasquez [1] have worked on the single phase conical shaped helical coil heat exchanger. The flow and the heat transfer in the heat exchanger were shown through this study. It was seen that through cone shaped helical coils heat exchanger the contours of velocity vectors were similar but there was an appreciable inclination of the velocity vector components in the secondary flow. It was seen from the study that some of the deviations and errors were due to the non- uniform flame radiation and condensed combustion products. J.S. Jayakumar [2] observed that the use of constant values for the transfer and thermal properties of the fluid resulted in inaccurate heat transfer coefficients. Based on the CFD analysis results a correlation was developed in order to evaluate the heat transfer coefficient of the coil. The analysis was done on both the constant wall temperature and constant wall heat flux boundary conditions. It was found that the Nusselt numbers were highest on the outer coil and lowest in the inner side. Parameters like the diameters of the pipes, the Pitch Circle Diameters have significant effect on the heat transfer and the effect of the pitch is negligible. 
Timothy J. Rennie [3] conducted the study on the heat transfer characteristics of a double pipe helical coil heat exchanger for both counter and the parallel flow. Study was made on both the boundary conditions of constant heat flux and constant wall temperature. It was seen that the results from the simulations were within the range of the preobtained results. The overall heat transfer coefficients were determined for the dean numbers ranging from 38 to 350. It was seen that the overall heat transfer coefficients varied directly with the inner dean number. A major contribution on the overall heat transfer coefficient was of the fluid flow conditions in the outer pipe. In order to get higher overall heat transfer coefficient, the design of the outer pipe should get the highest priority.

J.S.Jayakumar,S.M.Mahajani, J.C.Mandal, Rohidas Bhoi [4] studied the constant thermal and transport properties of the heat transfer medium and their effect on the prediction of the heat transfer coefficients. An experimental setup was made for studying the heat transfer along with the CFD simulation of the heat transfer. The results obtained through the CFD simulation were reasonably well within the range of the experimental results.

Usman Ur Rehman [5] conducted a study on the heat transfer and flow distribution in a shell and tube heat exchanger and compared them with the experimental results. An average error of around $20 \%$ in the heat transfer and the pressure difference was seen. It was seen through the study that the symmetry of the plane assumption worked well for the length of the heat exchanger but not in the outlet and inlet regions. Due to not much interaction between the fluids, the heat transfer was found to be on the lower side. The design could be improved by improving the cross flow regions instead of the parallel flow.

Nawras H. Mostafa, Qusay R. Al- Hagag [6] conducted the study on the mechanical and thermal performance of elliptical tubes used for polymer heat exchangers. Through the mechanical analysis it was seen that the streamlined shape of the outer tube had an optimal thermal performance. A finite element solution was determined for strain as a function of the material of the tube.

\section{Modelling And Cfd Analysis:-}

In order to conduct the analysis of the double tube helical coil heat exchanger, the coil was modelled in the ANSYS Modeler via Workbench. The helical coil modelled for the present study has following dimensions:-

Outer diameter of outer tube- 0.875 inch

Inner diameter of outer tube- 0.785 inch

Outer diameter of inner tube- 0.625 inch

Inner diameter of inner tube- 0.545 inch

Pitch circle diameter- 3 inch

Height of helical coil- 4inch

The model prepared in ANSYS Modeller was meshed in ANSYS Meshing software. The minimum mesh size was $0.4 \mathrm{~mm}$, maximum face size $1 \mathrm{~mm}$ and maximum mesh size $1.5 \mathrm{~mm}$. The mesh obtained was fine mesh with 751735 nodes and 725892 elements respectively. The name selection were done to specify inlet and outlet of inner and outer tube.

Model obtained is given in the fig.1.

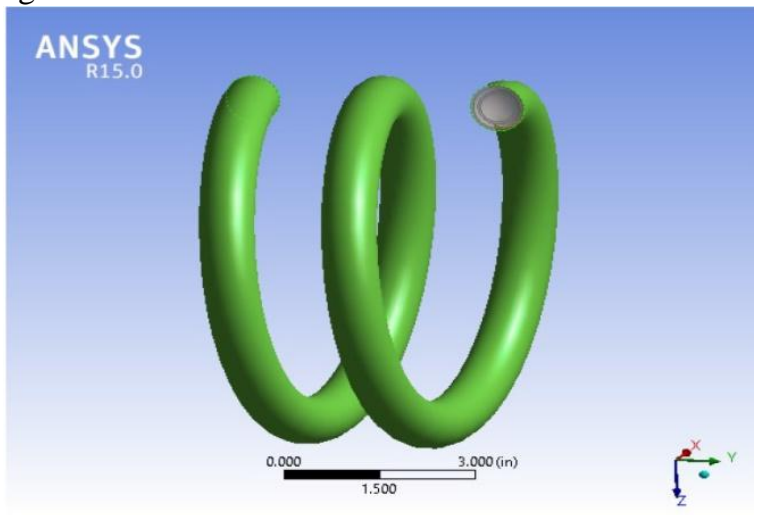

Fig.1:- 
Now this model was exported to ANSYS Fluent 15.0 software. the gravity was applied in Z- direction. The energy model, viscous k- epsilon (2 eqn.), radiation (discrete ordinates) model were selected. The working fluid and coil material selected for analysis were water and copper respectively. The boundary conditions selected are given below.

Table.1:-

\begin{tabular}{|l|l|l|l|l|l|}
\hline & $\begin{array}{l}\text { Boundary } \\
\text { condition type }\end{array}$ & $\begin{array}{l}\text { Velocity } \\
\text { magnitude } \\
(\mathbf{m} / \mathbf{s})\end{array}$ & $\begin{array}{l}\text { Turbulent kinetic } \\
\text { energy } \\
\left(\mathbf{m}^{\mathbf{2}} \mathbf{s} \mathbf{s}^{2}\right)\end{array}$ & $\begin{array}{l}\text { Turbulent } \\
\text { dissipation rate } \\
\left(\mathbf{m}^{2} / \mathbf{s}^{3}\right)\end{array}$ & $\begin{array}{l}\text { Tempe- } \\
\text { rature } \\
(\mathbf{K})\end{array}$ \\
\hline Inner inlet & Velocity inlet & 0.9942 & 0.01 & 0.1 & 348 \\
\hline $\begin{array}{l}\text { Inner } \\
\text { outlet }\end{array}$ & Pressure outlet & & & & \\
\hline $\begin{array}{l}\text { Outer } \\
\text { inlet }\end{array}$ & Velocity inlet & 0.8842 & 0.01 & 0.1 & 283 \\
\hline $\begin{array}{l}\text { Outer } \\
\text { outlet }\end{array}$ & Pressure outlet & & & & \\
\hline
\end{tabular}

Solution method was selected as simplec with standard pressure, least squares cell based gradient, first order upwind discrete ordinates and second order upwind energy, turbulent dissipation rate, turbulent kinetic energy and momentum. The residuals for continuity, X-velocity, Y- velocity, Z-velocity, energy, epsilon, do-intensity were selected as $10^{-6}, 10^{-6}, 10^{-6}, 10^{-6}, 10^{-9}, 10^{-3}, 10^{-6}$ were selected to obtain more accurate result. Standard initialization method was selected and the solution was initialized. The number of iterations were set to 1000 .

Same process were repeated for coil with $1,1.5,2,2.5$ turns.

\section{Results and Discussions:-}

For coil with 2 turn, the number of iterations required to converge the residuals were 658 . The graph for the residual vs. iterations is shown in Fig.2.

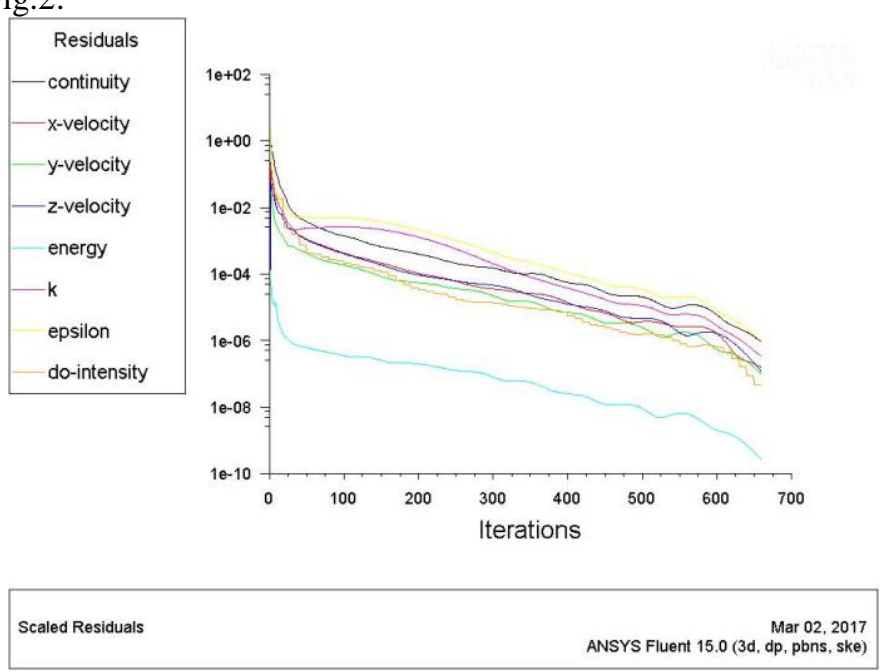

Fig. 2:-

The temperature contours for the coil having 2 turns is shown in Fig.3. 


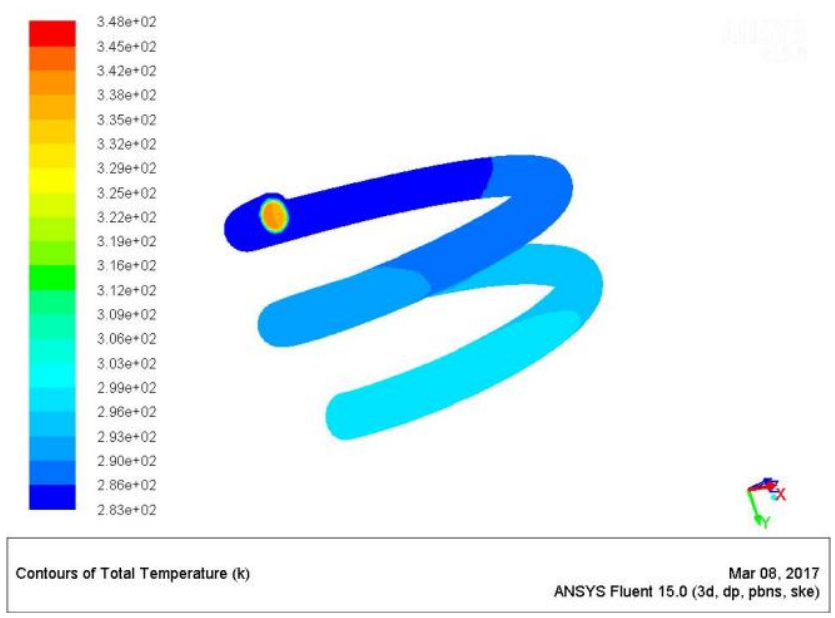

Fig.3:-

The pressure contour for the coil having 2 turns are shown in Fig.

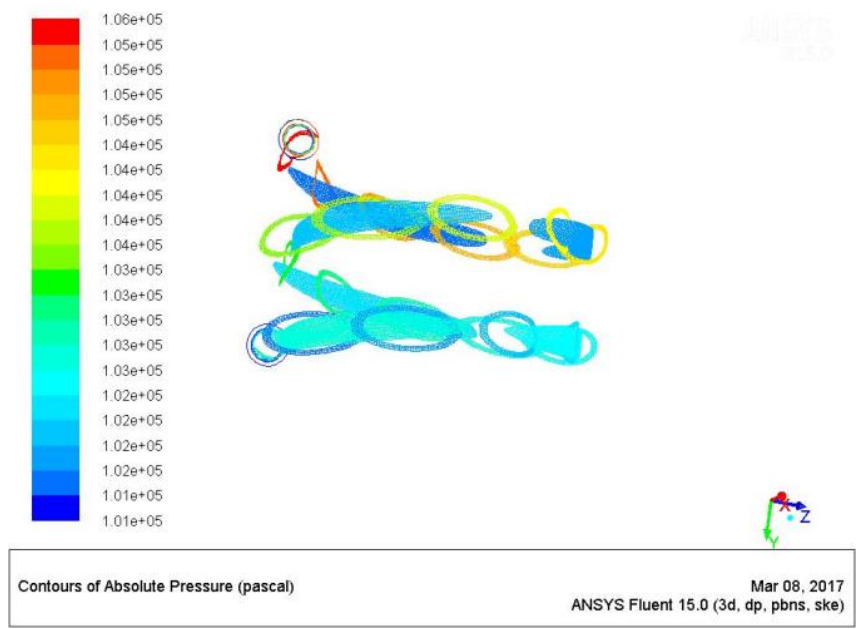

Fig.4:-

The maximum temperature drop was seen in two turn coil and least in one turn coil hot fluid. The heat transfer rate was maximum for two turns and minimum for one turn.

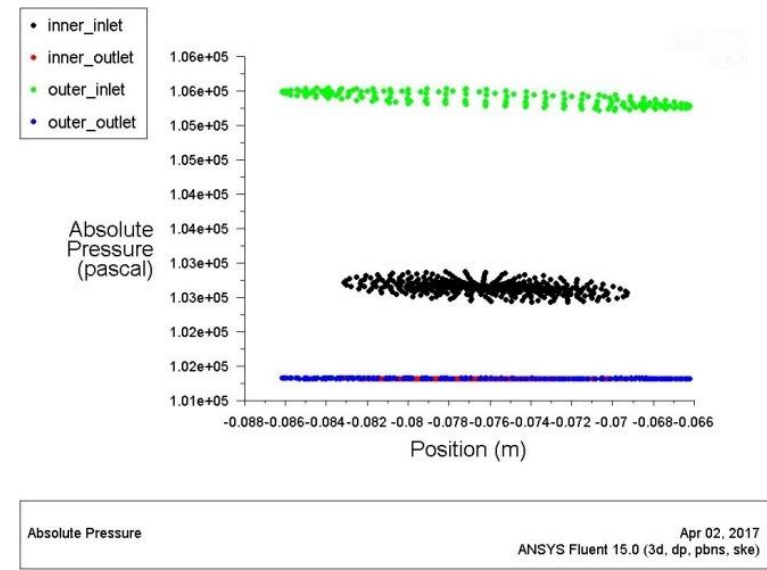

Fig.5:- 
From above graph it can be seen that the pressure drop between inlet and outlet is more outer tube as compared to inner tube.
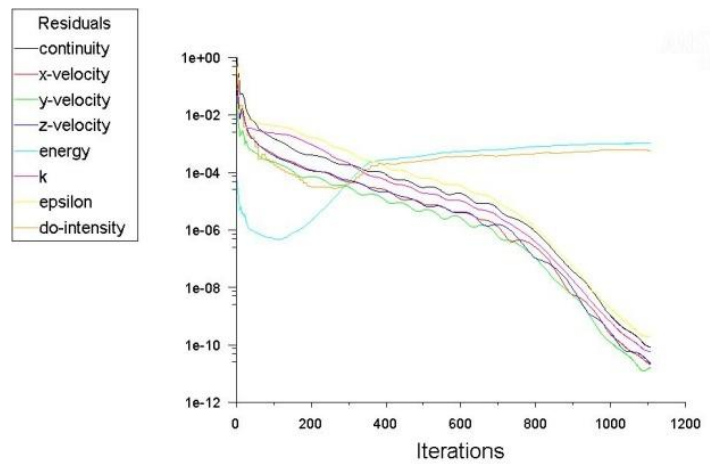

Scaled Residuals Apr 02, 2017
ANSYS Fluent 15.0 (3d, dp, pbns, ske)

Fig.6:-

The residual for 2.5 turns were found to be diverging as number of iterations were increased. This behavior shows that the boundary conditions were not appropriate for 2.5 turns.

\section{Conclusions:-}

1. As the number of turns increases the temperature drop of hot fluid also increases.

2. The increase in number of turns results in higher rate of heat transfer.

3. Temperature at the outlet of hot fluid was found to be more at the location far from the coil axis as compared to nearer location.

4. As the number of turns increases, the absolute pressure inside the coil also increases. And it is maximum at inlet section of outer cold fluid.

5. The pressure at the inlet of outer fluid is maximum at the location far from the coil axis as compared to the nearer location.

\section{Refrences:-}

1. Daniel Florez- Orrego,.2012. Experimental and CFD study of a single phase cone- shaped helical coiled heat exchanger: an empirical correlation. ECOS.

2. J.S. Jayakumara, S.M. Mahajania, J.C. Mandala, Kannan N. Iyer a, P.K. Vijayan,.2010. CFD analysis of singlephase flows inside helically coiled tubes. Computers and Chemical Engineering 34. 430-446.

3. Timothy John Rennie,. 2004. Numerical and experimental studies of a double pipe Helical Heat Exchanger. Dept. of Bio- resource Engg. McGill University, Montreal.

4. J.S. Jayakumar, S.M. Mahajani, J.C. Mandal, P.K. Vijayan, Rohidas Bhoi,.2008. Experimental and CFD estimation of heat transfer in helically coiled heat exchangers. chemical engineering research and design 86 . 221-232.

5. Usman Ur Rehman,.2011.Heat transfer optimization of shell-and-tube heat exchanger through CFD studies. Chalmers University of technology.

6. Nawras H. Mostafa Qusay R. Al-Hagag,.2012. Structural and thermal analysis of heat exchanger with tubes of elliptical shape.IASJ,Vol-8 Issue-3.

7. Dr. K.E. Reby Roy,. 2012. Numerical analysis of forced convection heat transfer through helical channels.IJEST, vol-4.

8. Minton P.E., may 1970. Designing Spiral tube heat exchanger. Chemical engineering. p.145.

9. Ender Ozden, Ilker Tari,.2010. Shell side CFD analysis of a small shell-and-tube heat exchanger. Energy Conversion and Management 51. 1004-1014.

10. D. G. Prabhanjan, G. S. V. Ragbavan and T. J. Kennic,.2002. Comparision of heat transfer rates between a straight tube heat exchanger and a helically coiled heat exchanger. International Comm. Heat transfer,volume. 29. No.2. pp. 185-191. 
11. Rahul Kharat, Nitin Bhardwaj, R.S. Jha,.2009. Development of heat transfer coefficient correlation for concentric helical coil heat exchanger. International Journal of Thermal Sciences 48. 2300-2308.

12. Vimal Kumar, Supreet Saini, Manish Sharma, K.D.P. Nigam.,2006. Pressure drop and heat transfer study in tube-in-tube helical heat exchanger. Chemical Engineering Science. $4403-4416$.

13. Nasser Ghorbani, Hessam Taherian , Mofid Gorji, Hessam Mirgolbabaei ,.2010. An experimental study of thermal performance of shell-and-coil heat exchangers. International Communications in Heat and Mass Transfer 37. 775-781. 